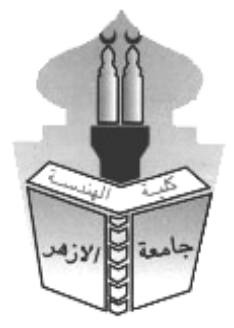

\title{
GREEN INFRASTRUCTURE TO ACHIEVE SUSTAINABILITY IN URBAN DESIGN Nile Corridor in Great Cairo as a Case Study
}

\author{
Amal Ahmed Abdou, Iman Osama Abd Elgawad and Tarek Mohamed Tarek Fouad \\ Architecture Dept., Faculty of Fine Arts, Helwan University
}

\begin{abstract}
In the last two centuries, societies have grown and the technology has developed, human activity had increased the negative effect on the critical natural systems that support life and vital to our sustainable occupation of this planet. The present days, especially after the Arab Spring revolutions, are perhaps the best timing for the Arab region's transition towards using the concept of green design in architecture and urban planning, where countries now are need of a new developmental approach that would ensure stability on both environmental \& economic levels, \& focus on the efficient use of natural resources.

The emergence of a new urban strategy, that considers the infrastructure design as a green sustainable network, gives the potential of a more livable balanced with natural systems, giving us a new definition for the green spaces at the urban plan level, and it is defined as Green Infrastructure (GI).

Green infrastructure can be considered our city's "life support system", as it represents a new approach to city planning that aims to minimize the human development impact on functioning natural systems, the quality of life \& has economic consequences. Jurisdictions that have applied Green infrastructure in their framework, realized the multiple ecological, financial, and community benefits.

KEYWORDS: Green infrastructure, Sustainability, Urban design, Green spaces, Potentials 1. INTRODUCTION

GI is referred to a strategically planned and managed network of green spaces and other natural features vital to the sustainability of any urban area, for both new and existing settlements, both rural and urban areas, which is designed to enable people to fulfill their basic needs and get numerous ecological services.

Therefore, this research aims to address Green infrastructure through a literature review and focuses on factors related to it. After that, it discusses the Nile corridor in Great Cairo Region (GCR) as a case study for possible GI potentials in Egypt. Finally, conclusions \& recommendation were addressed.
\end{abstract}

\section{GREEN INFRASTRUCTURE}

\subsection{Principles of Green infrastructure}

Green infrastructure principles need to act as a guide for strategic planners. ECOTEC (2006) considered that strategic regional principles for Green infrastructure is being integral of the urban growth framework, where it offers a powerful planning tools \& creates links between scale, size, function, type \& form. Benedict \& McMahon (2002) suggested critical principles to the success of GI initiatives;

A. Strategically designed, planned and delivering 'smart' conservation at different scales, building connectivity in ecological networks and promoting green spaces in the urban environment.

B. Delivering multifunctional benefits; designing and managing land as a multifunctional resource capable of delivering a wide range of environmental and quality-of-life benefits.

C. Helping to deliver place-making; recognizing the character and distinctiveness of different locations and ensuring that policies and programs respond accordingly. 


\section{Engaging key partners and involving diverse stakeholders.}

\subsection{The Benefits and Potentials of Green Infrastructure}

Green infrastructure solutions are defined, as planned and managed natural \& semi-natural systems that can provide more categories of benefits, compared to traditional gray infrastructure, $\&$ aims to success upon the sustainable resilient of the nature's ecosystems. Greca et al (2010), affirm the potential of green infrastructure in terms of environmental, social, \& economic benefits, through coordinated planning of the natural environment in communities and providing multi-functionality for both human activities and natural resources; supporting quality and design, by reducing urban pollution \& adapting to climate change, by involving communities in the design process and with stakeholders in the planning process, and finally investing in the future, so that the Green infrastructure involves a long-term conservation, implementation, improvement of monitoring performances every while, and maintenance agenda, with funding from government and private partnerships.

Environmental impact of Green Infrastructure: GI through its natural elements and its techniques such as green roofs, green walls, street trees and non-vehicular travel routes as walking and cycling, can reduce heat-induced, reduce the fuel consumption, and reduce air, water $\&$ soil pollution. Connected Green infrastructure assets can create wildlife corridors to enable species movement, more resilient biodiversity in the face of changing climate effects. This network has additional importance in creating linkages between existing urban areas and new landscape areas via linear blue elements such as streams and canals within natural green elements such as parks and linear routes. (Davies, 2008)

Social impact of Green Infrastructure: GI creates green spaces, within the urban building blocks; it can be a focus for community participation through public involvement in the design, delivery and management of new assets, as well as providing opportunities for education, training and volunteering. GI also reduces health inequalities, improves mental well-being by providing access to the nature and attractive green spaces, encourages physical activity by providing quality green spaces for walking, cycling, sports and playing, helps in growing food locally and healthy eating, and reinforces the local landscape character and a strong identity which make people will be proud for their area. Therefore, transforming school grounds to green spaces would provide experiential learning facilities \& reconnect children with nature, as a fundamental principle of living within environmental limits \& a foundation of sustainable development.

Economic Impact of Green Infrastructure: Green infrastructure elements are available with affordable cost as they are a local natural component of the urbanized local areas (Burden, 2006). Sustainable Cities Institute in England, stated that local governments have begun to experience the benefits that attend the strategic development of their green infrastructure system, such as; A) Increased property tax revenue; Homebuyers have been shown willing to pay as much as 33 percent more for land adjacent to protected green space. B) Strengthen local economic development; Businesses look to locate and expand in localities that have access to outdoor and recreational spaces. C) Less-required government services; Green spaces generally require much less public service than developed land.

\subsection{Scale Range of Green Infrastructure Practices}

Green infrastructure should be thought about at every scale of planning, from the strategic framework right down through neighborhoods and within streets to the building; Site level, covering rooftop and wall surfaces with green and vegetation since they cover a big portion of built surface area. Street level, encouraging smart and appropriate planting in street design, which helps soften the street scene by creating visual interest \& improving the microclimate. Neighborhood level, integrating with existing roads, paths and surrounding development, creating opportunities for easy and suitable access into the green network and avoiding bad siting of buildings which could block the access to the green network. Strategic level, thinking how development can join up to the existing green network, by providing plugs to the gaps in the strategic green network and landscape setting, and having benefits to the new development by providing good connections and a continuous network of routes. Individual green elements can serve the purpose of green infrastructure without being connected, but when these elements are linked together to form green networks, further combined benefits can be achieved.

\subsection{Green Infrastructure vs. Grey Infrastructure}

The key differences between green and gray infrastructure, help identify the specific areas of opportunity for optimum resilient infrastructure which are often combinations of new GI solutions integrated into existing facilities, creating so-called hybrid solutions, the key differences are as follow; 
- In GI, extended stakeholders have an active role in the project design \& operation, while in gray infrastructure, they don't have this role.

- GI requires a custom-made, location-specific design, but traditional solutions use standards, reducing project costs and delivery times.

- Operational and maintenance costs of GI are low (only monitoring \& feedback is required) and insensitive to changes in the cost of raw materials, oil, gas and power, but Gray infrastructure costs are higher due to power use, and very sensitive to the price volatility

- GI needs no 24/7 operational supervision, as traditional solutions do in control \& safeguarding system.

Utilizing a combination of green and gray infrastructure, hybrid approaches, may provide an optimum solution to shocks and improve the overall resilience of an organization. For example, gray components may support the growth phase of green infrastructure projects, or vice versa.

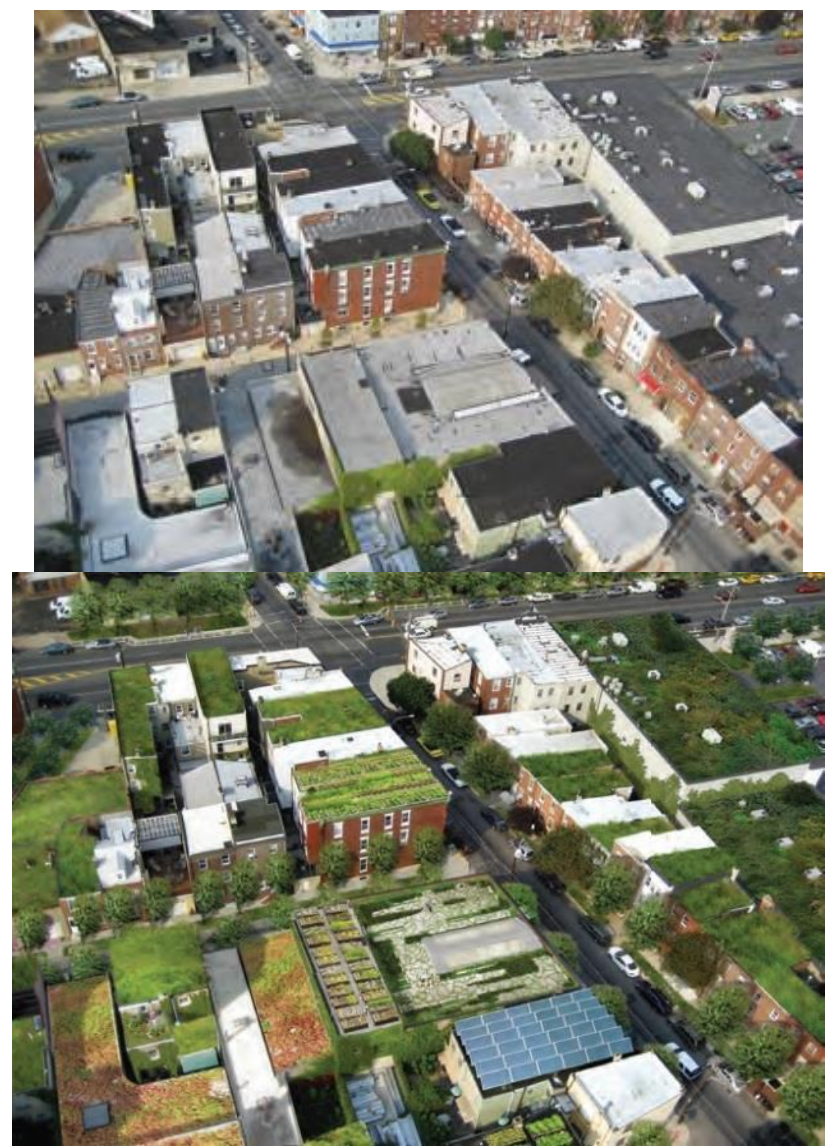

Figure (1-1) Before (Left) \& After (Right) depiction of ways that green infrastructure might transform part of South Philadelphia. Source: http://inhabitat.com/nyc/new-initiative-explores-how-green-roofs-canbring-jobs-andenvironmental-benefits-to-harlem/philadelphia-green-roof-before-and-after/

\section{CASE STUDY: Green corridor along the River Nile}

The term 'green infrastructure' is more popular in Europe and America than in Middle Eastern arid countries. GI don't have the same meanings and properties in arid zones as it does in humid zones. Therefore, GI projects in Middle Eastern countries depend on factors such as irrigation from rivers, conduits, streams or wells. Understanding nature's evolved responses and adaptations to conditions of aridity and observing the landscape forms that derived from those adaptations might be used as basic models for arid \& semi-arid regions. (Lyle, 1996)

Bashandy (2003) focuses on the historical establishment of greenways and green networks system from the beginning of 20th century in Cairo. The greenways are now considered to be a connector between public open spaces network and pedestrian paths, based on the River Nile \& its conduits, as a main source of irrigation. In GCR, it acquires additional importance, because it "ventilates" the most populous parts which lack sufficient open spaces and leisure facilities. That's why the Nile and its 
banks are one of the most important sources of environment, tourism \& leisure $-\&$ an economic key resource - of Cairo.

\subsection{Criteria of the Case Study}

In order to study the present "green" network and to evaluate its potential as GI, River Nile corridor was selected for investigation. This choice was based on available information that permitted study of key aspects. The criteria are as followed;

- Geographical location: It stretches from North to South, incorporating GCR, \& includes three islands.

- Climate: The climate is a desert climate. There is virtually no rainfall during the year. The average annual temperature is $21.3{ }^{\circ} \mathrm{C}$ and the average precipitation is $18 \mathrm{~mm}$.

- Scale: Metropolitan scale, connecting different urban settlements.

- Functions and connections: Functionally divided into two main sectors; islands and river banks.

- Associated activities: This corridor is divided into three main sections:

1) Activities along Riverbank: entertainment, angling clubs, and floating ships.

2) Activities on the Nile waterfront, i.e. commercial and residential activities.

3) Activities on islands: agricultural lands and protected areas.

- Density of vegetation: It spreads along the River banks as greenways \& open spaces, \& on the islands.

- Shape: A linear axis links different types of human activities and urban settlements.

\subsection{Analysis of Case Study}

The main theme of this case is a combination of the socio-cultural value associated with the customs and traditions associated with heritage places, together with the powerful natural feature of the River Nile and its banks, providing connectivity between natural, social and economic elements. This case will be presented in two sections: a description and documentation the River Nile and its banks; and a critique and analysis, commenting on the gaps between Nile master plans and the implementation process.

\subsubsection{Description \& Documentation}

In Cairo, the Nile River connects different districts processing distinctive characteristics. It is the main blue way that includes natural, visual, environmental, agricultural and economic functions. Importantly, it links historic Cairo, the main ring roads \& connects the network of open spaces along the River. These linkages enhance the connectivity of existing GI elements (Figure 1-2). Figure (1-3) show examples of landmarks on the visual line along the River Nile.

(Fig. 1-2) The districts connected by the River Nile, Source: Google Maps

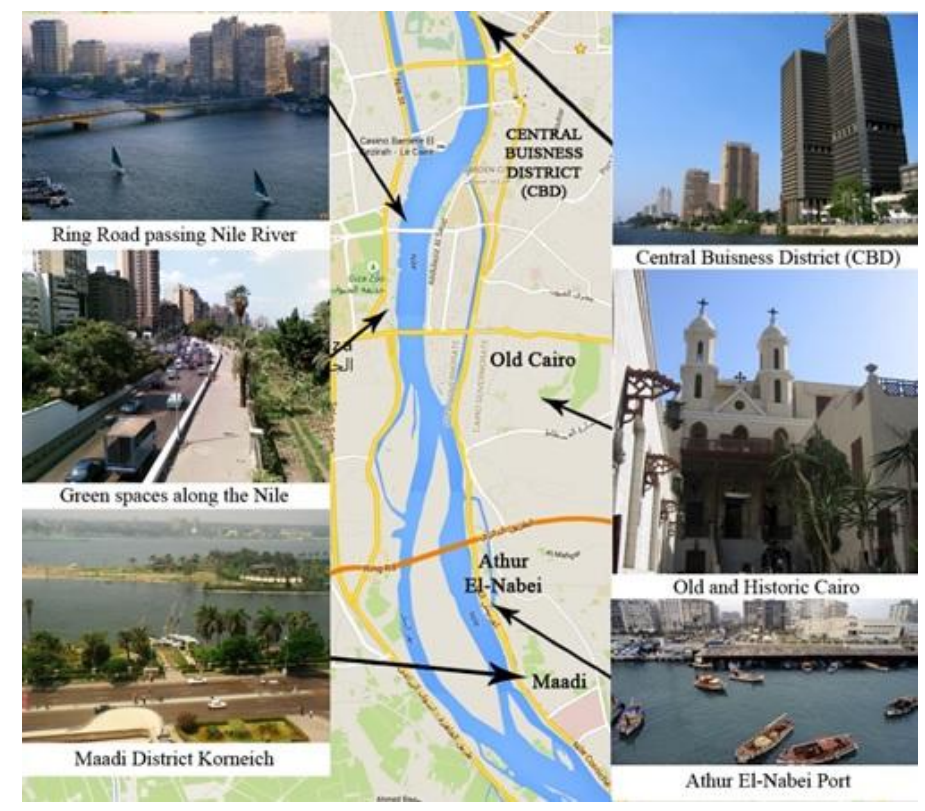




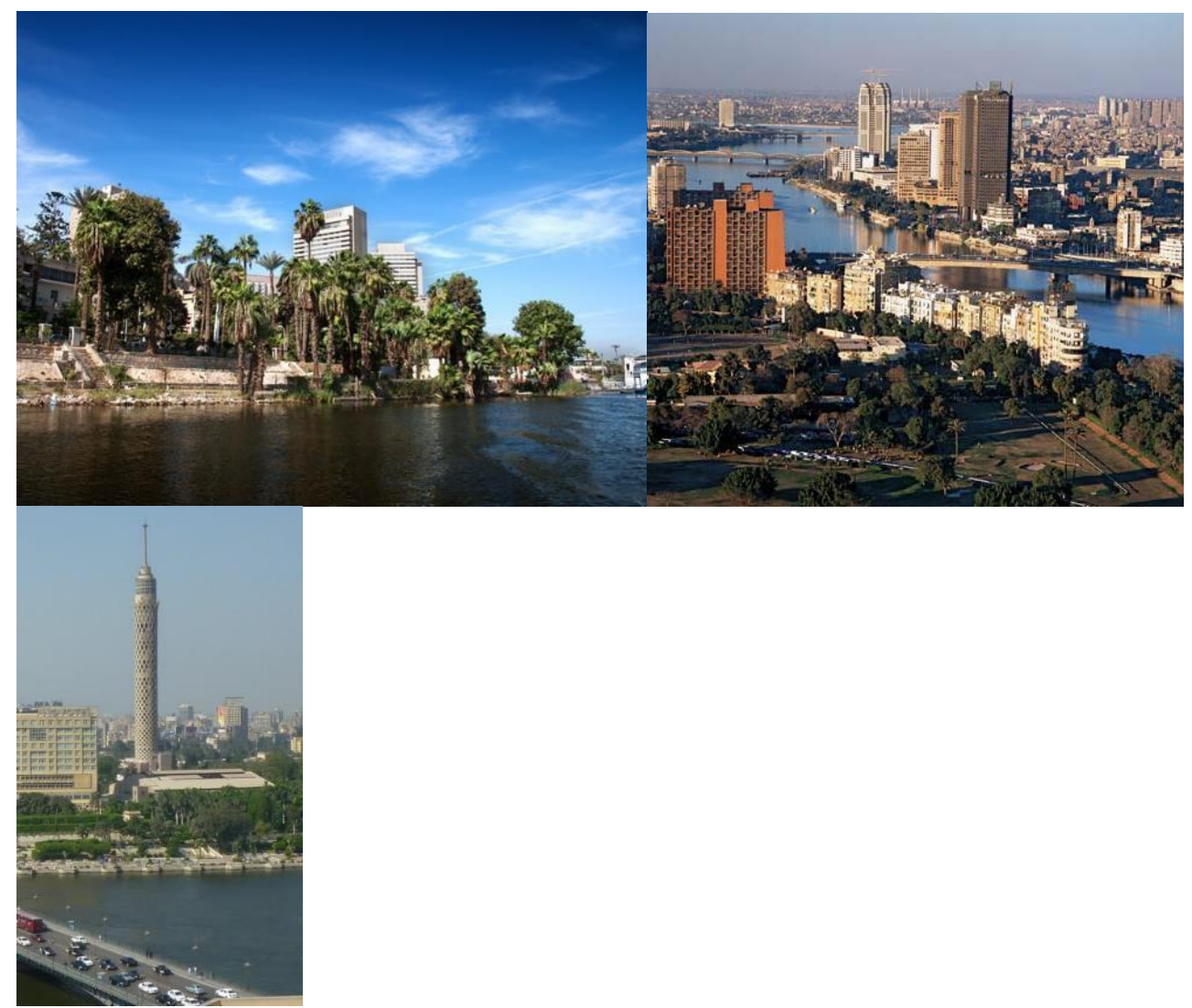

(Fig.1-3) Palm trees in green patch, Distinctive urban character, Cairo Tower as an iconic building.

\section{Aim and objectives of this case study}

Source: Researcher

The River Nile as a natural blue way connecting cultural, historical, touristic and recreational features. Potentially, it possesses a robust natural infrastructure encompassing the social network of multi-functional green spaces and green corridors which improves the quality of life for residents and visitors in the area as well as for the whole Cairo City.

GI planning objectives might be delivered via the Nile Vision, including developing visual and movement corridors along river banks; improving access to and along the river within the city through the provision of public transport and a network of pedestrian paths, bridges, ferries, bicycle paths and marinas; increasing the continuity of public open space along the River Nile, as a 'parkway' linking parks and recreational areas; and high investment in River transport within Greater Cairo and upgrading of touristic marinas and recreation along the River Nile and its islands. (Barada et al, 2005)

\section{Planning Strategy}

Barada et al (2005) have proposed a policy that provides a framework for GI, namely: preserve agricultural lands on the banks of the urban areas and the Nile islands; control the growth of urban communities through the protection of rural space; \& solve the problems of urban sewage and agricultural drainage. River banks have the potential to be recreational riverside greenways, which could underpin a GI based on cycle ways along the River, pedestrian paths, open green spaces, parks, and green space parallel to the Nile. The River is seen as the spine of a major recreational network linking the touristic and leisure hubs of the River Nile with the green and open spaces, and archaeological and cultural sites within GCR. Furthermore, this vision considers the needs of economic activities associated with the River Nile. This would be reinforced by transforming the communication networks that link with central commercial areas into greenways through extensive landscaping. These linkages with their various natural, historic, cultural and recreational functions, suggest the possibility of a connective and multi-functional GI. 


\subsubsection{Critique and Analysis \\ Policy-implementation gaps in the Nile master plans}

There are different master and structural plans concerning the development of the River Nile and its banks, recommending activities and land uses around it and also proposing projects to develop and broaden the role of the River Nile. However, many recommendations \& projects failed to be implemented due to a major lack of co-ordination between planning organizations. Thus, the Master Plan was issued by the Municipality of Cairo without coordination between other planning organizations such as the General Organization for Physical Planning (GOPP) and the Ministry of Housing, Utilities and Urban Development (MHUUD). The plan sought the creation of recreational green access intersecting with river banks; at the same time, the GOPP prepared a proposal to develop the major and minor vehicular roads. Thus, two different agencies were advocating different functions to the same road.

In addition, there was a great lack of public awareness at the 1954 Master Plan, people were not aware of the importance of Nile or of developing its cultivated lands. People were not familiar with the concept of a green network \& did not engage with government decisions, as their needs did not match this concept.

After that, the structural plan of 1983 promoted the development of the Nile waterfront of ELDahab and Zamalek Islands as protected areas and their banks as recreational areas. However, these policies were not implemented for reasons mentioned in the 1991 Structural Plan, namely, luxury housing spread into these areas and also various land uses were changed to be high investment buildings such as hotels and business centers. Thus, these changes of land use reveal a conflict between the MHUUD, landowners and parliamentary legislation. Landowners ignored legislation and governmental decisions to invest their money in recreational activities as these yield relatively little profit.

The 1997 Master Plan suggested creating connections between Nile activities and urban districts, through a green belt. Some of this green belt was implemented and was intended to be a starting point for a green network. However, the proposed green belt was abandoned to absorb the population growth of Cairo.

In 2005, GOPP and MHUUD co-operated to increase the green areas and recreational activities along River Nile. They also developed the Nile waterfront and promoted replacement of residential areas on the Nile Islands to become natural protected islands and to improve Nile transport.

However, the Cairo Vision 2050, in 2009, recommended major and minor green corridors along the River Nile, different recreational activities and touristic facilities around the river banks. Some of these projects are now supported by spatial planning studies, such as the development of Syalt EL-Roda Bank, within the recreational potential, green open spaces, pedestrian \& cycle way (Fig. 1-4). Others are in progress, such as EL-Dahab Island, which has not yet become protected due to problems of relocating its residents.
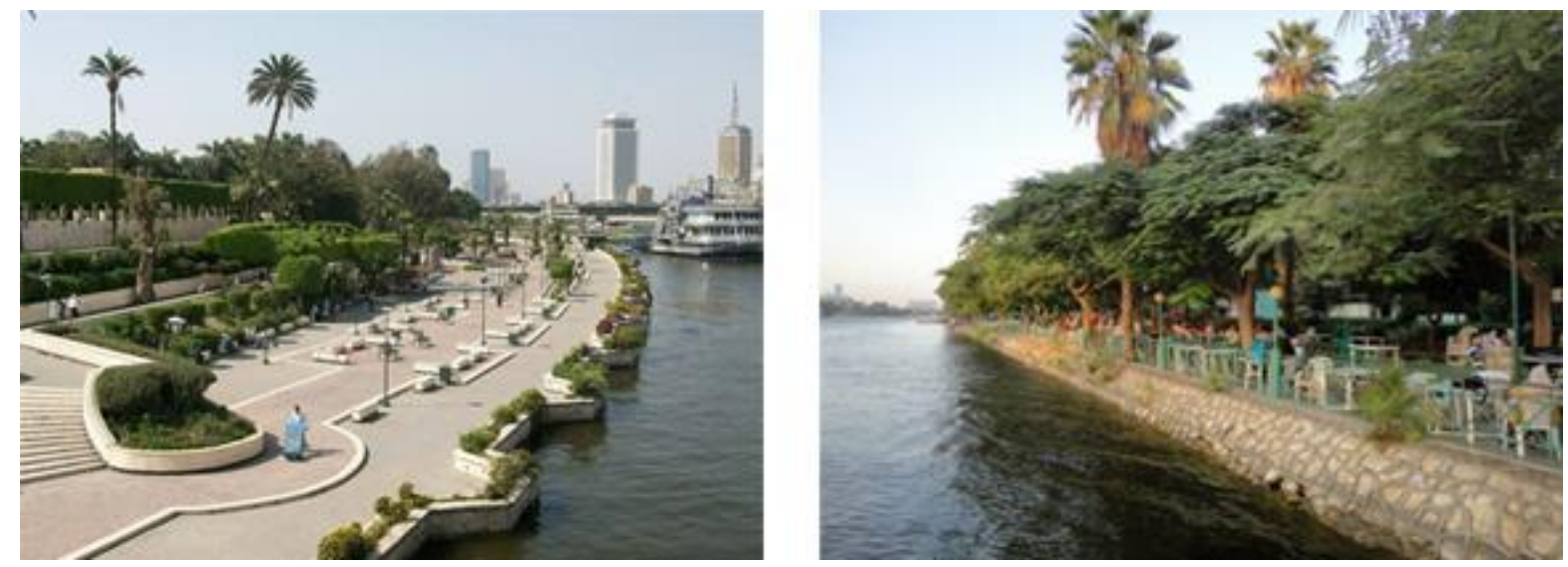

(Fig. 1-4) Different recreational activities within social clubs in Syalt EL-Roda Bank. Source: Researcher 
It would appear that to achieve implementation on the ground, the following weaknesses need to be addressed: (1) lack of people' awareness regarding importance of Nile as a vital corridor; (2) lack of co-ordination between different planning \& urban organizations such as GOPP \& Urban Research Consulting Centre; and (3) conflict between, urban \& planning legislation.

Narrowing the policy-implementation gap requires overcoming various shortcomings. First, regarding the lack of people' awareness, there should be a process of informing and involving all the habitants around the River, users of its activities, \& stakeholders that are concerned with the development of Nile. Second, to overcome the lack of co-ordination between different planning organizations, it is recommended that the planning system should include a specific organization that is responsible for overall co-ordination between different organizations. Third, regarding deficiencies and conflicts in urban \& planning legislation, the legislation also needs to restrict the side effects of buildings along the River banks, and determine the amount of Nile water use for irrigation of the surrounding cultivated lands. This will enhance the connectivity of green corridor along the River Nile, and emphasize its multifunctionality related to various recreational activities and environmental features.

Green Infrastructure potential in the River Nile Case Study area; the potential for GI in this area is considered in terms of three key criteria; connectivity, multi-functionality \& sociocultural sustainability.

\section{Connectivity}

The River Nile is a natural, social and economic link which connects different islands through the waterway and links different urban districts via major roads. Also, it links different human $\&$ recreational activities via the greenway along its banks. Together, these areas represent the natural connections of habitats, green spaces and hydrology and man-made connections from roads and circulation access.

In terms of green spaces, the River Nile connects three islands which have different kinds of open green space. ELZamalek Island has public green spaces along the Island Bank; an opera house as a cultural feature \& private open green spaces inside AL-Gezeira Club. Syalt EL-Roda Island has many recreational activities based on green areas such as the linear Nile green park and the green corridor connecting the heritage axes. EL-Dahab Island and its green lands support cultivated areas. In the front of these Islands along the River banks, considerable numbers of recreational attractions enhance the connectivity function and improve its natural value, socio-cultural customs and historic places. From a hydrological point of view, the River Nile is the main blue way for different functions and uses; it is the main source of drinking water, irrigation for agriculture and recreational sites, and is a means of transportation for people, communities and tourists. Thus, it improves the economic base and possesses social and environmental values. Moreover, there are different conduits, lakes and streams from the River Nile that serve different agricultural lands and urban districts that do not have direct access to the main body of River Nile. However, there are no existing hydrology features apart from the River Nile. Before the end of 19 th century, there were two conduits. One was the major stream that branched from the Nile at EL-Roda Bank to supply Medieval Cairo with water. This stream was filled in at the end of the 19th century to be used as a major road connecting historic Cairo with New Cairo. The second was started from EL-Dahab Bank to supply Maadi District with

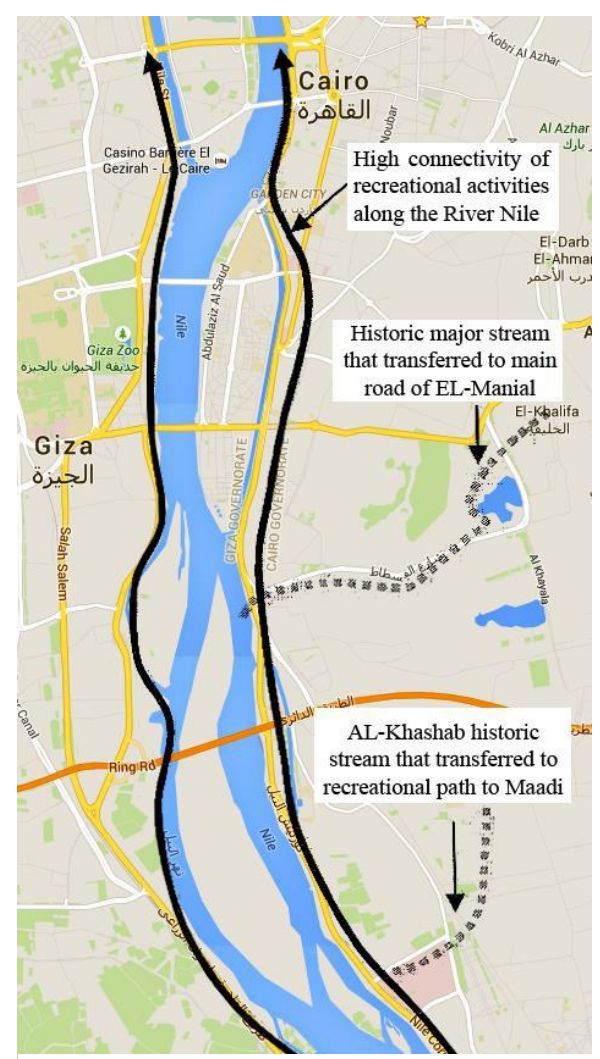

Figure (1-5) Connective activities along, and the lost conduits of, the River Nile.

Source: Google Earth accessed in 25.08.2015 water when it was mainly agricultural land. However, this stream was filled in and converted to grey infrastructure because of encroaching urban development and the growth of Maadi District (Figure 1-5).

In terms of circulation, it is important to consider both vehicular and pedestrian movements along the Nile. The study area includes the major Nile Way (Corniche) and there are different 
major and minor roads intersecting with the Nile Way such as Salah Salem highway and 15 May Road, The Corniche is well maintained and provides opportunities for one continuous route along the River bank and Greater Cairo. Also, in some sectors of River Banks, there are cycle ways beside the pedestrian paths, particularly, in recreational places such as the cycle way along the River Nile in Syalt EL-Roda Bank. Therefore, these types of circulation can increase the connectivity between natural \& functional elements.

In terms of connectivity - the green spaces, hydrology and circulation - the natural corridor is the River Nile and its banks. This links the greenway along the River Nile with various functions; it improves the social and economic values and enhances recreational value, helps moderating the micro-climate using special native plants and ground water recharge, improves the quality of food production and reduces the expense of irrigating agricultural lands. Moreover, the connection between the islands and their banks strengthens the relationship between historic and natural places and helps to develop environmental education and public awareness. The linkages along the River Nile and its surrounding urban areas shape the natural, functional grid that is based on the length of the River and its intersecting axes.

Multi-functionality

The River banks are, or have the potential to be, recreational riverside greenways that include cycle ways along different parts of the river, pedestrian paths, social clubs, open green spaces, parks, and green space parallel to the Nile especially in the urban and recreational sectors. Currently, these islands are residential \& agricultural areas, suffering from lack of clean water. Recent studies have investigated the needs of the economic activities along the River side such as touristic marinas, transportation along the River Nile and commercial areas. The investigations highlighted the primary need for an effective connecting network composed of several levels of greenways and green corridors, which would connect not only the activities along the River, but also these activities with central commercial and cultural areas in the main part of the city (Mahmoud \& Selman, 2009). The Nile River as a waterway can fulfill different functions such as boat marinas, water sports and River cruises (Fig.1-6). The current study therefore identifies the value of a zonal approach to the River corridor, based on functions and natural divisions.

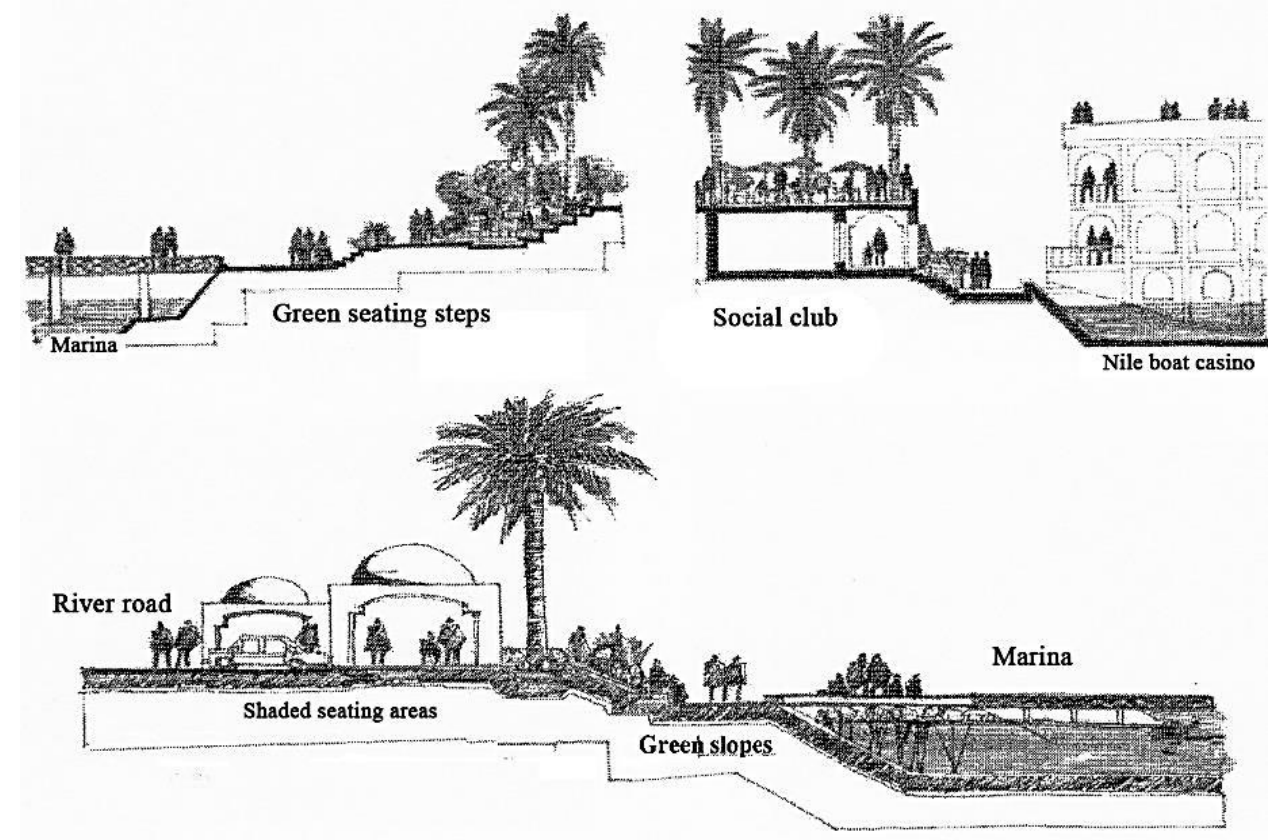

(Fig.1-6) The social attractions on the River Nile banks that improve the economic value from its income and develop the recreational and touristic facilities along the River. Source (Noha M. 2009)

Zone 1, AL-Zamalek Island and its eastern bank; Main function of AL-Zamalek Island \& its eastern bank zone are recreational function associated with active $\&$ passive leisure. The Gezira Club is the 
most extensive green space designed \& established in modern Cairo, alongside other prestigious landmarks, such as Cairo opera house \& the Cairo tower (Fig. 1-7).

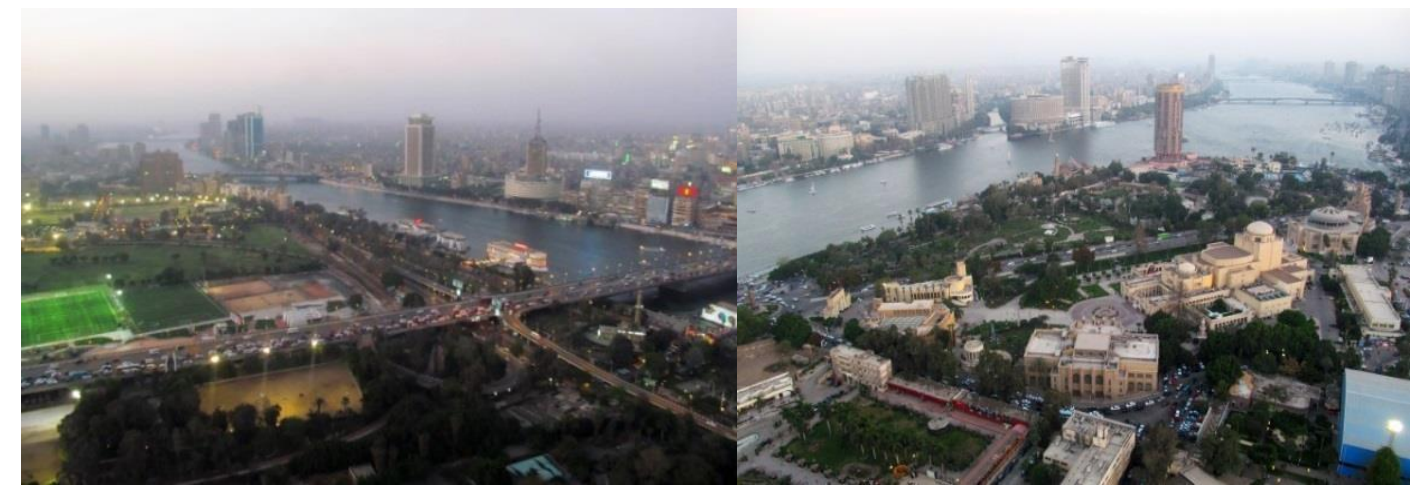

Figure (1-7) Recreational functions in AL-Zamalek Island and its banks. Left: green spaces in Gezira sporting club. Right: Opera cultural centre and the public Nile Park. Source: Researcher

Also, the Island is well known for having fashionable residential districts with green nodes and a lot of private schools. Accordingly, this study suggests a recreational center that links the River's landmarks, green spaces, social clubs, cycle way, commercial malls and other recreational activities within residential areas. These kinds of activities will increase the connectivity between recreational elements and improve the quality of vegetation, increase active recreation and moderate the microclimate to reduce air temperature via luxuriantly vegetated routes. Therefore, the scope for connectivity and integration suggests a possibility to establish a recreational center in the eastern bank of AL-Zamalek Island. This proposed recreational center could include open spaces, green areas, social club, hotels, cycle way, green axes and a commercial mall, and their functions integrate with the existing recreational activities that surrounding this center (Figure 1-8).
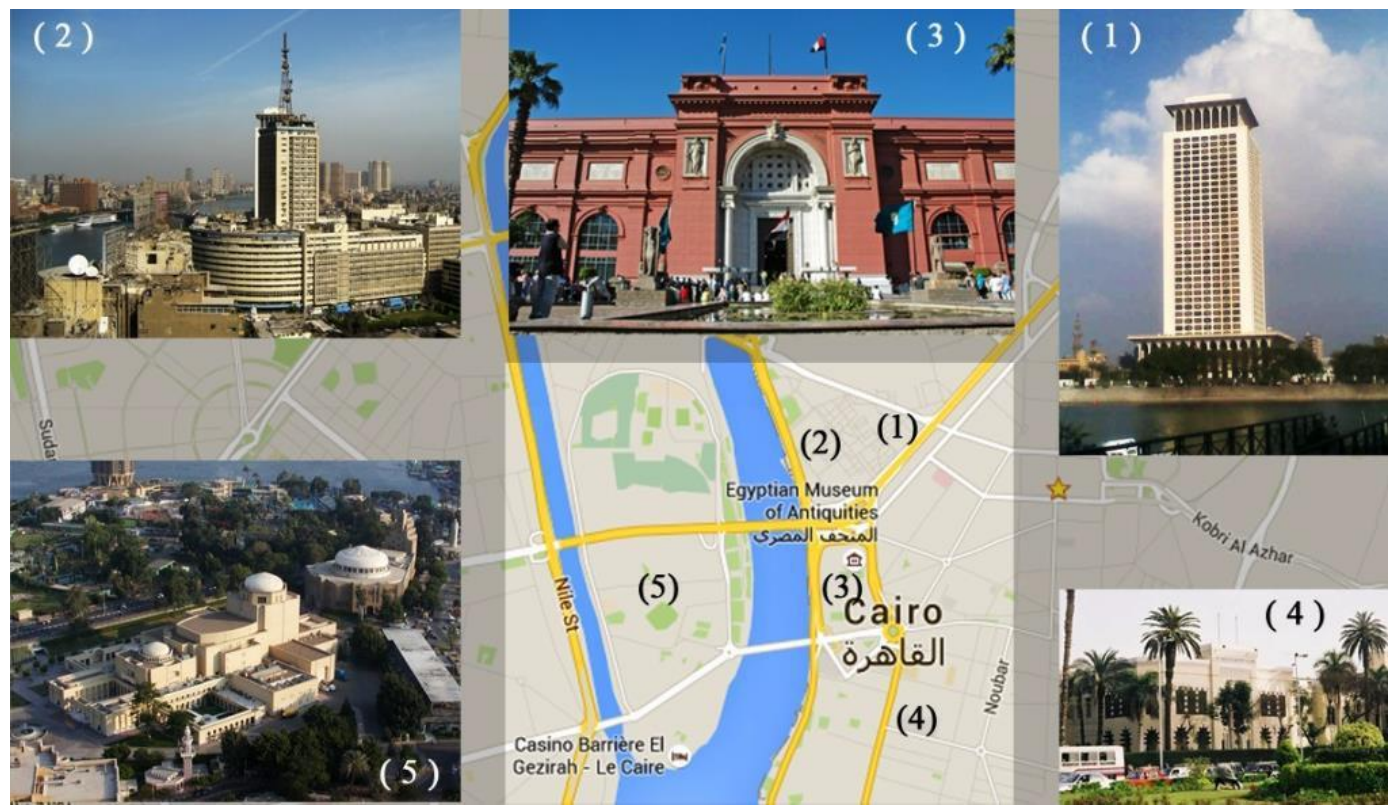

Figure (1-8) Major landmarks of AL-Zamalek and Syalt EL-Roda Islands; The Egyptian Muesum, Media building, Opera and Cairo University campus highlight the major points of cultural corridor. Cairo

Tower, famous hotels and Nile parks are a core part of the recreational corridor along River Nile. Source (map and photos): Google Maps

Zone 2, Syalt EL-Roda Island and its eastern bank; this zone appears to be suitable as a heritage, historic and cultural corridor. The researcher proposed a historic cultural corridor that connects four main axes: the Compound of Religions axis, the great mosque of Amr Ibn 
AL-Aas axis, the Khaleg Garden axis and the Ministrly Palace Garden and Nilometer axis. These axes connect the historical city with the River Nile corridor via a strong visual axis to the waterfront of Nile. Therefore, the proposed cultural corridor links all these four axes from the South to the North along the bank of River Nile in the front of Syalt EL-Roda. Moreover, this linking axis can be designed as a sequence of River gardens that accommodates all the leisure activities associated with these four axes. Further, it would seem sensible to connect these axes together through the main corridor, the River Nile bank of Syalt EL-Roda. Also, they could be linked by the roads that intersect with the Nile axis such as AL-Manial Street \& bridges like AL-Malek AL-Saleh Bridge. This connection between historic elements improves cultural values for people.

Importantly, it has a variety of vegetation and horticultural lands that help to cool the climate, developing a visual image of green linkage. Increasingly, some trees are also used in food production such as date palm, fig tree \& banana tree. Also, they provide timber in this zone, such as Cyperus papyrus \& bamboo.

Zone 3, EL-Dahab Island and its eastern bank; the main function of EL-Dahab Island is agriculture. The government has decided this should be a protected land and offered new places for the local inhabitants to move out. However, some of island's inhabitants refuse to comply with this decision and still remain on the Island, and have the support of the Habitat International Coalition (HIC, 2009).

Harris (2009) describes programs to bring education to the residents, training inhabitants to preserve the natural places on Island and to be aware of their rights. Ezzat (2010) refers to the socio-economic problems in this island such as high transportation prices and poor quality boats, limited number of schools at all educational levels and a limited number of utilities such as hospitals. However, environment is one of the most important issues for this Island. The agricultural land is based on Nile water for irrigation (Fig. 1-9). Animal and crop wastes are thrown directly in the Nile. Also, the waste drainage system is a serious cause of pollution to the Nile, and environmental damage is also being caused by the encroachment of urban areas $\&$ removing agriculture. This island is a stopover for migratory birds such as white stork and little gull, and it provides habitat for other species such as the endemic frog, Bufo kassasii, and different kind of Nile fish such as Mugil cephalus and Solea vulgaris.
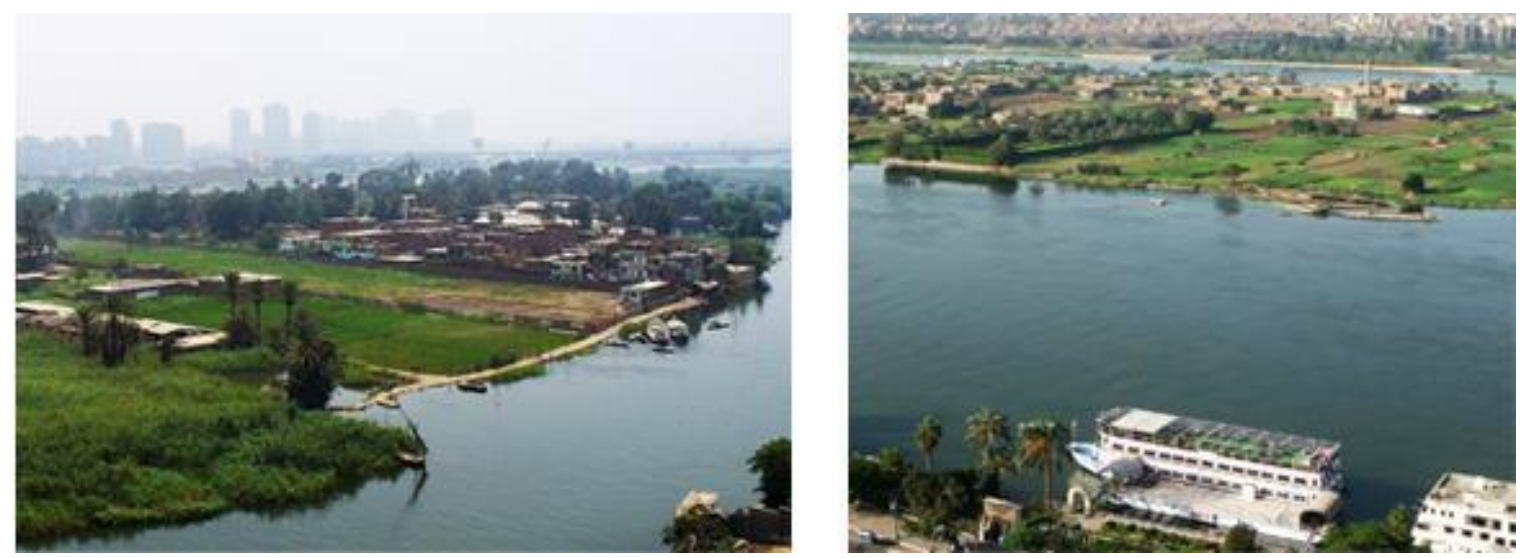

(Fig. 1-9) The agricultural lands of EL-Dahab Island based on an irrigation system directly from River Nile. Source: Google Earth

The western side of the River Nile, which fronts onto these Islands, has mixed uses. The dominant use is residential and it is supported by different recreational functions from small gardens, open spaces and social clubs. Also, commercial and governmental buildings spread along the River bank. These functions help and support the multiple functions on these three islands by connecting visually and functionally via the Nile. Additionally, the eastern river bank from the island includes Ather EL-Naby port that is the main access to the island and which has an industry zone and some storage areas for building materials. 


\section{Socio-cultural Sustainability}

This natural corridor connects different cultural assets through cultural axes that include heritage and historic places. Some traditions and customs occur in public spaces along the River Nile, for example, the Nile festival and celebration of the Nile flood. This event is called Cairo's Wafaa Al-Nil Festival (Fidelity of the Nile). This festival was a reminder for people of the importance of the Nile. Nowadays the celebrations focus only on the arts, poetry, concerts and scientific discussions. This celebration takes place in public spaces on the Syalt EL-Roda bank and events are organized by the Ministry of Culture. This study suggests different green and open spaces that join with existing open spaces to form a completed part of green structure around GCR. Thus, these three multi-functional zones will connect with the recreational activities along the River by main green axes that will enhance the coherence of the green corridor along the Nile in terms of its multi-functionality, connectivity and sustainability.

\section{CONCLUSIONS \& RECOMMENDATION}

The general focus has been on the GI meanings, components and principles within sustainable planning strategies. Then, a detailed focus on GI in Greater Cairo, as an example of an arid area which can be based on valuable corridors, networks and linkages. These valuable features should include cultural and historic resources that have great social values for communities.

First of all, there is a need to embed a GI, as appropriately conceived through academic analysis and professional skills. It should build on an understanding of the existing network based on the natural features of places. Also, it should commence with comprehensive and international studies within different fields that relate to GI, and integrate green and grey infrastructure.

And to implement any GI project, it is essential to have a specific planning process accompanied by good management. There needs to be a suitable organization that can overcome the lack of coordinated decision making and long term planning. Effective planning legislation is necessary to coordinate all levels of the planning process.

To sum up the River Nile Case study, the holistic approach of the greenway of open spaces, pedestrian paths, cycle ways and other recreational functions together will improve access and circulation between adjacent urban districts and recreational access along the River Nile. Increasingly, it will develop the natural, economic, touristic and cultural values for communities backing away from Nile. The natural value is very clear from the blue way, which has lush vegetation and abundant wildlife. Economic functionality could be developed via the recreational and commercial functions along the River banks and also via the Nile River-bus and cruises. The cultural value is the most important one in this case besides the natural value, focusing on the heritage and traditional historic communities. Consequently, the connection between all these values throughout the major natural way, i.e. the River Nile, and via different green corridors, will improve the concept of GI in Cairo. This addition of economic, social and cultural values to the concept of GI emphases its importance as a sociocultural and not solely "environmental" corridor. Moreover, this corridor should be robustly linked to a hierarchical network of multi-functional green spaces with access to a range of recreational activities. Consequently, this will improve the quality of life and will reflect the River Nile as a main connector of social life in Cairo within a sustainable management and planning strategy.

The geographical features of the Nile blue way and its cultivated lands have led the governmental and private organizations to build up different recreational activities that are supported by natural elements of river and vegetation. Most of these projects are under governmental management. However, some private projects override governmental legislation in the Nile corridor, creating a big gap between private organizations, government aims, and people's needs.

Finally, from the research, it recommends specific planning aspects to redevelop or create natural infrastructure in arid areas. Most arid countries in the Middle East share similar environmental conditions, although they might have some differences in their natural resource base. However, GI in arid areas has been strongly connected with two main aspects: planning strategies and irrigation systems. For the planning strategies, success will depend on recognizing GI as the basic, connecting layer of the planning strategy. It is necessary to 
expand on traditional green space and recreation strategies, so as to include natural and environmental resources, as well as involve a wide spectrum of participants and ensure timely implementation. For the irrigation system, the development of the drainage and irrigation system is the most important facet of GI projects in arid areas, especially in combination with distinctive topographic features. The irrigation system depends on re-cycling waste-water (grey water) and groundwater recharge, but its unnecessary use can also be minimized by using special native plants and by educating people and decision-makers about climatically appropriate types of open space.

\section{REFRENCES}

1. Barada, A., Steno, M., Tulan, N., and Yousry, M. (2005) The Planning and Urban Studies of River Nile: Master Plan of River Nile Banks of Greater Cairo. Faculty of Regional and Urban Planning (FURP), Cairo University, Cairo.

2. Bashandy, S. (2003) The Water Courses Within the Framework of System Ideology Themes for Environmental and Green Corridors: Proceedings of the Al-Azhar Engineering 7th International Conference (AEIC) held at Al-Azhar University. Cairo, Egypt. P.162-179.

3. Benedict, M. A. and MacMahon, E. T. (2002) Green infrastructure: Smart Conservation for the 21 st Century. Renewable Resources Journal, 20 (3), 12-17.

4. Burden, D. (2006) Urban street trees, 22 benefits, Specific applications Retrieved from

5. http://water.epa.gov/infrastructure/greeninfrastructure/index.cfm

6. Davies, C. (2008) Green infrastructure. Clive Davies Associates Ltd. [Online] Available from

7. http://clivedaviesassociates.com/3.html

8. ECOTEC (2006) City Region Green Infrastructure strategic planning: Raising the quality of the North's City Region. ECOTEC, Leeds, UK, p. 6-24.

9. Greca, P., Rosa, D., Martinico, F., and Privitera, R. (2010) Agricultural and Green Infrastructure: The Role of Non-Urbanised Areas for Eco-Sustainable Planning in a Metropolitan Region. Environmental Pollution, Article in press, doi:10.1016/j.envpol.2010.11.017.

10. Harris, M., (2009) Geziret Ed-Dahab Island, Cairo, Egypt: Inhabitants Face Expulsion to Give Way to Private Development Projects Under Cairo's Intended Urban Master Plan for 2050. The Egyptian Centre for Housing Rights (ECHR), Cairo.

11. Habitat International Coalition (HIC) (2009) Geziret Ed-Dahab Island, Cairo, Egypt: Inhabitants Face Expulsion to Give Way to Private Development Project. Framework of the Land Forum, Cairo.

12. Lyle, J. T. (1996) Archetypes in Arid Landscapes. In: William Reilly (ed). Sustainable Landscape Design in Arid Climates. Geneva, Aga Khan Trust For Culture. p.25-37.

13. Mahmoud, N. and Selman, P. (2009) Connecting Natural Infrastructure in Spatial Planning in Arid Zones: Proceedings of the Ecological Networks: Science and Practice Conference held at Edinburgh University, TALE UK, Edinburgh. p.97-112. 